\title{
Study on the Image Preference for the Development of the Application for the Gas Safety Field Workers
}

\author{
JooAh Lee ${ }^{1}$, Mi-Hye Kim ${ }^{2 *}$ and Bong Hee Kang ${ }^{3}$ \\ ${ }^{1}$ Department of Christianity, Ewha University, Korea, 120-750 \\ ${ }^{2}$ Department of Computer Engineering, Chungbuk Nat'l Univ, \\ Cheong-Ju, Korea, 362-763 \\ ${ }^{3}$ Tri et Mono, Chungbuk Do, Korea, 362-763 \\ 1joojooah@hanmail.net,2mhkim@cbnu.ac.kr
}

\begin{abstract}
This study aims to design for an application for the Gas Safety field workers. At first, we did a research on the features and nature of the gas safety field work and its workers in order to draw the requirements for creating the basic contents, and then conducted a survey on the image preference of the workers that could best convey the contents.
\end{abstract}

Keywords: Mobile App, Gas Safety related Application, UI/UX, Design Image Preference, Labors

\section{Introduction}

As digital devices become an intrinsic part of our lives, a broad range of applications are being introduced every day. These applications together with computer programs and games were provided largely in the maker-driven way at the early development stages. However, with more emphasis on user-convenience and user-experience, the application developing process has been changed to tailor to specific target group's need which leads to do more pre-studies on images or interfaces most appropriate for the application's purpose.

This study aims to find out preferred images to be used in the application for the workers in gas safety field operations. Fuel gases are not only one of the major energy resources, but a dangerous substance with lots of accidents involved in working process. To reduce the risk at gas field work, it is required to develop an application to alert workers on what is going on during operations as well as to enhance safety awareness and improve working environment.

For the digitally vulnerable group of people, particularly, the application should be as simple as possible, adopting eidetic images with structurally simple design. Given gas field workers' limited access to smart devices and their working environment, the initial stage to develop the application is choosing the right images that can be easily recognized. Both high-quality contents and visually effective designs are key factors to be a successful application. In light of this, it is critical to adopt images that can well reflect specific and various occasions in field operations and be promptly recognized by the users. Using such an application at field work can lead to an increase in safety and job satisfaction for the employees and better performance and reputation for the company. With few preceding researches, it is hoped that the image preferences outlined in this paper will allow to help develop more applications that can be used in many different field work places.

${ }^{*}$ Corresponding Author 


\section{Method and Procedure}

This study utilized literature investigation, interview, and indirect data collection, which followed five phases of procedure: (1) needs analysis based on the research on the features and nature of gas field operations and its workers (2) break down the work process and occasions that can happen during the field operations and draw matching images from the list (3) make a list of assumptions to put on the app (4) survey on image preferences and (5) verify the assumptions through quantitative analysis and finalize sampling the preferred images.

\begin{tabular}{|c|l|l|}
\hline Phase & Content & Description \\
\hline 1 & Needs Analysis & $\begin{array}{l}1 \text { Research on the nature of field workers } \\
2 \text { Research on the features of gas field } \\
\text { operations }\end{array}$ \\
\hline 2 & $\begin{array}{l}\text { Designing } \\
\text { Basic Structure }\end{array}$ & $\begin{array}{l}3 \text { Breaking down field operation process } \\
4 \text { Drawing images on each process }\end{array}$ \\
\hline 3 & $\begin{array}{c}\text { Making } \\
\text { Assumptions }\end{array}$ & $\begin{array}{c}5 \text { Making assumptions describing the } \\
\text { possible occasions during field operations }\end{array}$ \\
\hline 4 & Surveying & $\begin{array}{c}6 \text { Survey on image preferences on each } \\
\text { process and occasion }\end{array}$ \\
\hline 5 & Conclusion & $\begin{array}{c}7 \text { Verifying assumptions via quantitative } \\
\text { analyis Sampling preferred design images }\end{array}$ \\
\hline
\end{tabular}

\section{Needs Analysis Based on the Nature of Gas Safety Field Workers}

Categorized as 'realistic' by Holland model, gas field workers are committed to dealing with high-pressure gas facilities and other field operations, generally defined as bluecollar workers. Psychologist John L. Holland suggested that there are six personality types: realistic, investigative, artistic, social, enterprising, and conventional.

According to Holland, 'realistic' people are likely to fit into the occupations of car mechanics, gardeners, farmers, police officers, technicians, and agriculture teachers. They are physically active, good at handling tools and machinery and enjoy being involved in activities of fixing, repairing and building, but are shy of spotlight and feel comfortable when working independently. As for the field workers, a few preceding researches indicate that field workers are far more exposed to noise, light, high humidity, dust, heat, rays, toxic and foul substances than office workers, meaning chances are that they are open to be in more stressful environment and this causes them to prefer simple colors like primary or secondary colors. In addition, most of the field workers are male workers and they show a high level of likability on blue color.

As these exiting researches on the image and color preference stand on gender basis, not pointedly on the field workers, this study referred to Holland Occupational Themes and a small number of researches on colors and designs had brought together the information about gas safety field workers of the level of their smart device proficiency, sociality, and interactivity in order to draw user requirements. The results are as follows: 


\section{Needs Analysis on the Requirements of the Gas Work Field Based On the Characteristic}

Korea Gas Safety Corporation (KGS) divides gas field work into two areas: large industrial facilities including nuclear power plant and steel factory where highpressure, toxic gases are used, and storage and supply facilities for domestic and commercial purposes such as LPG, LNG, and city gas. Both facilities, different in scale and size, pose high risks of gas leaks and followed poisoning, explosion and conflagration.

Gas-related accidents are classified into six cases according to KGS and this can be re-labeled under three categories: (1) gas leaks including poisoning and suffocation due to the leaks, (2) conflagration, and (3) explosion.

- Leakage: gas leaking but not develop to fire or explosion

- Explosion: gas explosion caused by gas leaking or fire after the explosion

- Conflagration: fire by leaking gases' combustion, but not gas explosion or destruction accidents

- Poisoning: casualties due to gas combustion or toxic gases

- Suffocation(hypoxia): casualties due to lack of oxygen

- Destruction(rupture): destruction of gas facilities, gas container or gas appliance caused by physical or chemical reactions

The requirements of the application can be deduced as seen below:

It will be required to

1) find out the images that can convey the clear message of 3 major accidents - gas leaking, conflagration, and explosion. The image of gas leaking, most frequent accident, should be the top priority.

2) pick up eidetic colors that can alert of 'danger' as quickly as possible.

3) do a research on various images that can reflect the urgency.

Outside of big accidents like gas leaking or explosion at gas field operations, slipping or falling is another common incident at the site and industrial facilities are at a greater risk of slipping and falling due to its large structure. Compared to the direct gas-related accidents, slipping and falling accidents are not an emergency evacuation incident, but far more frequent so that extra attention is needed. Furthermore, large industrial facilities set designated areas where workers must do their jobs with special care according to the type of gases and works. Hence following requirements can be drawn.

It will be required to

1) have the image that indicates the places where slipping and falling occur often.

2) have the images that clearly inform of how much care is required by areas

saying "safe" "with care" and "caution".

Inattention is another reason for gas field accidents, which is because gas safety field workers basically do the repetitive jobs. According to a report on the causes of city gas accidents, more that $64 \%$ of the accidents occurred by inattention, of which $41 \%$ was due to missing double check and $31 \%$ was mere carelessness. These patterns of accidents take place in common for both large high-pressure gas plant 
and relatively small facilities like LPG or city gas. In this respect, it will be helpful to set up a ' check-it-out' system that gives workers an alarm on whether they are doing their jobs with proper safety measures or not, when extra care is needed, and so on throughout the daily operations, and ultimately it will lead to avoid and reduce the risk of individual worker' $\mathrm{s}$ failure.

Based on this, following requirements can be drawn.

1) An image of 'attention' is needed to avoid frequent errors whilst doing daily operations.

2) An image of 'operating safely' is need to indicate that workers are doing their job right.

To sum up the requirements discussed above:

\begin{tabular}{|c|c|}
\hline Criteria & Requirement \\
\hline \multirow{4}{*}{ Emergency } & Gas leaks \\
\hline & Conflagration \\
\hline & Explosion \\
\hline & Urgency level for evacuation \\
\hline \multirow{4}{*}{ Normalcy } & Indication for " Operating safely" \\
\hline & Indication for " Operating with care" \\
\hline & Indication for " Caution: Slip/Fall" \\
\hline & $\begin{array}{l}\text { Indication for " degree of the safety of the work } \\
\text { site" }\end{array}$ \\
\hline \multirow{2}{*}{$\begin{array}{c}\text { Images } \\
\text { Design }\end{array}$} & App icon \\
\hline & Display layout on mobile phones \\
\hline
\end{tabular}

\section{Survey Participants}

Sixty gas safety field workers participated in the survey and responded 100 percent. The profiles of participants are shown below.

\begin{tabular}{|c|c|c|c|c|}
\hline \multirow{2}{*}{ Gender } & Male & Female & \multicolumn{2}{|c|}{ (uni : } \\
\cline { 2 - 5 } & 100 & 0 & \multicolumn{2}{|c|}{} \\
\hline \multirow{3}{*}{$\begin{array}{c}\text { Service } \\
\text { Year }\end{array}$} & $\begin{array}{c}1 \sim 5 \\
\text { years }\end{array}$ & $\begin{array}{c}6 \sim 10 \\
\text { years }\end{array}$ & $\begin{array}{c}11 \sim 19 \\
\text { years }\end{array}$ & $\begin{array}{c}\text { more than } \\
20 \text { years }\end{array}$ \\
\cline { 2 - 5 } & 32 & 8 & 39 & 21 \\
\hline \multirow{3}{*}{ Age } & $20 \sim 29$ & $30 \sim 39$ & $40 \sim 49$ & More than 50 \\
\cline { 2 - 5 } & 28 & 12 & 49 & 11 \\
\hline
\end{tabular}




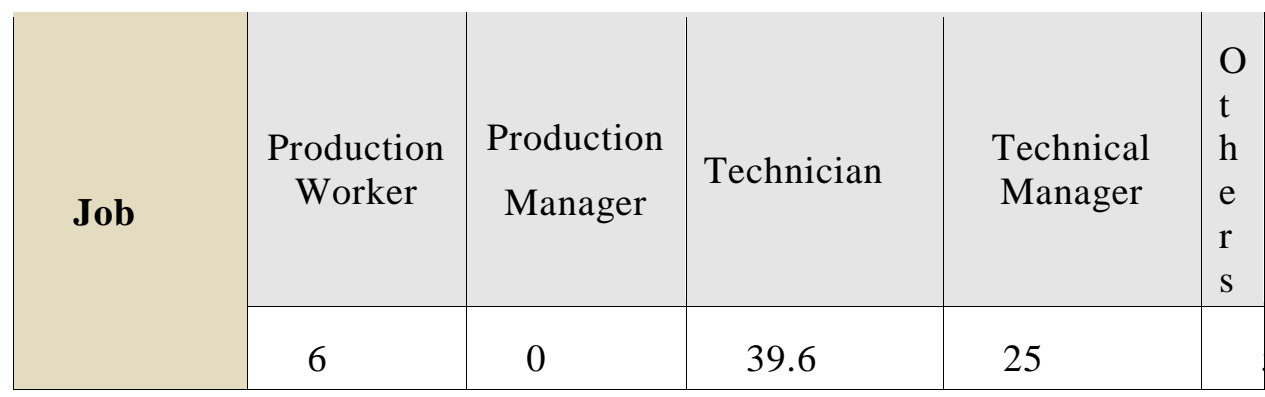

\section{Assumptions of the Survey}

Assumption 1. Below assumptions would be right regarding the images of emergency for the development of mobile app.

$1-1$. Red color would be preferred as sign of "danger."

1-2. Kinetic images would be preferred to describe the level of "urgency."

1-3. The gas mask image would be preferred to indicate "the state of gas leaking."

Assumption 2. Below assumptions would be right regarding the images of normalcy - operating safely, with care, safe order, slip or fall - for the development of mobile app.

$2-1$. The OK sign would be preferred to express "operating safely."

2-2. The exclamation mark would be preferred for the image of "operating with care."

2-3. The basic safety images would be preferred for "Safe orders."

2-4. Colors implicating the images of danger would be preferred for "Caution: Slip/Fall."

Assumption 3. Below assumptions would be right regarding the images of the application icons and design-safety, associated image of gas, display layout- for the development of mobile app.

3-1. Existing images with text would be preferred as "safety" programs.

3-2. For the picture of the main display, the image of their employer character (logo) would be preferred.

3-3. For the display layout for mobile phones, using 2 colors for buttons and 4 colors for the display picture would be preferred.

\section{Results}

Quantitative analysis method was used to verify the survey. The result is shown. below. 


\begin{tabular}{|c|l|l|}
\hline $\begin{array}{c}\text { Numb } \\
\text { er }\end{array}$ & \multicolumn{1}{|c|}{ Research Topics } & \multicolumn{2}{|c|}{ Results } \\
\hline $\mathbf{1}$ & $\begin{array}{l}\text { The indication sign for } \\
\text { "Danger" }\end{array}$ & The red color \\
\hline $\mathbf{2}$ & The degree of "Urgency" & A kinetic image \\
\hline $\mathbf{3}$ & $\begin{array}{l}\text { The image for "Gas Leak } \\
\text { situation" }\end{array}$ & A gas mask image \\
\hline $\mathbf{4}$ & $\begin{array}{l}\text { The image for "Operating } \\
\text { safely" sign }\end{array}$ & The "Okay Sign" \\
\hline $\mathbf{5}$ & The image for "Careful" & The "Exclamation Mark" image. \\
\hline
\end{tabular}

\begin{tabular}{|c|l|l|l|}
\hline 6 & The image for "safety Areas" & The basic safety image \\
\hline 7 & $\begin{array}{l}\text { The image for "Fall, Slip, } \\
\text { Careful" }\end{array}$ & $\begin{array}{l}\text { The colored images for "Fall, Slip, Careful" which indicates } \\
\text { danger }\end{array}$ \\
\hline $\mathbf{8}$ & The "Safety" program images & The existing pictures and textual images. \\
\hline $\mathbf{9}$ & $\begin{array}{l}\text { "Gas Safety" App loading } \\
\text { pictures }\end{array}$ & $\begin{array}{l}\text { Korean Gas Safety Corporation characters } \\
\text { picture }\end{array}$ & The button of two color, entirety four color \\
\hline 10
\end{tabular}




\section{Conclusions}

We did a research on the characteristics of the gas safety field work and its workers as the first step of the development of the application and came up with the requirements by analyzing their needs. Then, we conducted a survey to pick up field workers' preferred images for the application development, for the findings of the research indicated that most of them were conservative middle-aged men with little exposure to smart devices, had limited access to using any devices while working, using both hands during operations, and seemed to be more familiar with common and eidetic images. The result of the survey is as below.

1. Red color is preferred as a sign of "danger."

2. Kinetic images are preferred to describe the level of "urgency."

3. The gas mask image is preferred to indicate "the state of gas leaking."

4. The OK sign is preferred to indicate "operating safely."

5 . The exclamation mark is preferred for the image of "operating with care."

6 . The basic safety images are preferred for "Safe orders."

7. Colors implicating the images of danger are preferred for "Caution: Slip/Fall."

8. Existing images with text are preferred as "safety" programs.

9. For the picture of the main display, the image of their employer character (logo) is preferred.

10. For the display layout for mobile phones, using 2 colors for buttons and 4 colors for the display picture is preferred.

\section{Implication and Suggestion}

This study may give us implications for further use of it. Gas safety field workers turn out to have a strong inclination to conservative images, meaning the images that are simple, well-known and precise are preferred to novel, innovative and complicated images. It is well supported by the survey result that gas field workers chose the symbol of KGS rather than other refreshing natural objects as the main loading image of the safety program and old images were more popular than new images like safety helmet or text image as the images of 'safety zone' or 'gas safety program' application.

Thus, it is recommended to use familiar images or slightly changed existing designs rather than creating completely new images when developing an application for gas field work. Also, enjoyment together with convenience cannot be overlooked when it comes to designing user experience, given the survey result saying using 2 colors for buttons and 4 colors for the display picture is preferred as for the display layout.

\section{Limitation and Direction}

It becomes more popular to develop applications for specific user groups and UI/UX design by age or professions such as programs for children education or housewives. Considering the fast growing mobile application market, it is expected that customer groups of applications will be expanded from general and large population groups to relatively small and specialized user groups like hearingimpaired people or specialists.

As pointed earlier, gas field work is exposed to frequent accidents great and small, and particularly accidents at industrial facilities such as nuclear plant, steel factory, and marine facilities will have a great impact on our life and can cause huge loss of property and casualties. Due to this, studies are under way in many countries outside Korea, with building networks between objects and gas facilities in order to enhance safety and lower accident rate. This study was the initial step to find out a way to 
catch up with these circumstances as the concept of UI/UX is now at the early stages in Korea. With this regard we can put a significance on this study although it was a brief survey. To strengthen the reliability of this study, it may need to consider further studies as follow.

1) Study with bigger sample size to increase the reliability of the quantitative analysis

2) An extended survey on the image preference for more various situations at gas field work based on this study (e.g., images of gas ventilation, emergency exit, evacuation pose, first-aid, ladder/rope for rescue)

3) Doing the same survey with different field workers to verify the consistency of this study assuming that the result of the study would be same with the result of other field workers including female workers at large discount stores or city gas facilities and to see if the result of this study represents the preference and features of gas safety field workers only.

\section{Acknowledgements}

This research was financially supported by the Ministry of Trade, Industry and Energy(MOTIE) and Korea Institute for Advancement of Technology(KIAT) through The promoting regional industry for growth-based-linked.

\section{References}

[1] K. Seung Gyun, K. Bum Su, Y. Jae Mo and P. Sang Jun, Korean Gas Association, vol. 338, (2014).

[2] B. Young Jung, Design and Human Engineering, Min Young, Seoul, (2014).

[3] J. Sung Ho and Y. Jung Hee, "Mobile Application Design Project", Information Publishing Group, Seoul, (2011).

[4] D. Kim and J. Jung, IJSEIA, vol. 8, no. 1, (2014), pp. 44.

[5] J. L. Holland, "Making vocational choices: a theory of vocational personalities and work environments", Odessa, Los Angeles, (1997).

[6] P. Zervas, I. Kalimeris and D. Sampson, "A Method for Developing Mobile Virtual Laboratories", Proceedings of IEEE 14th International Conference on Advanced Learning Technologies, Athens, Greece, (2014) July 7-10.

[7] D. Lee, IJAST, vol. 32, no. 118, (2011).

[8] H. Gyun won, "Occupational Safety and Health Practice”, Hyuong Sul, Seoul, (2005).

[9] K. Mi-Hye, L. JooAh and K. Bong Hee, ASTL, vol. 86, (2015), pp. 102-105.

[10] S. Djamasbi and T. Tullis, AMCIS, vol. 8, no. 7, (2007).

[11] H. Kim, IJSEIA, vol. 7, no. 3, (2013), pp. 387-389.

[12] S. W. Kim, H. K. Jo and D. Y. Ha, Lecture Notes in Computer Science, (2011), pp. 444-448.

[13] Korea Gas Safety Corporation, 2013 Annual gas accident, accident casebook of high-pressure gas, gas professional practitioners accident casebook, KGS, Seoul, (2013).

\section{Authors}

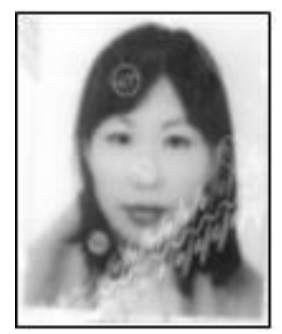

Joo-ah Lee is aLecturer Department of Christianity, Ewha Womans University. She received Ph.D degree in Christianity from Ewha Womans University, Korea in2011, respectively. She is currently a Lecturer of the Department of Computer Engineering in Chungbuk National University, Korea and Ewha Womans University, Korea. Her research interests are in the field of ICT Healing Contents, Storytelling, and Serious Games. 


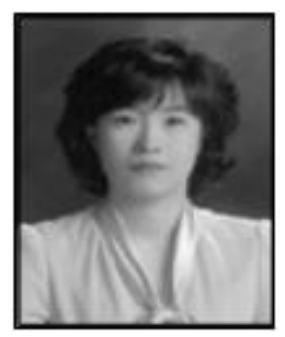

Mi-Hye Kim is a Professor of Department of Computer Engineering, Chungbuk Nat'l University.

She received B.S, M.s, and Ph.D degree in Mathematics from Chungbuk National University, Korea in 1992, 1994, and 2001, respectively. She is currently a professor of the Department of Computer Engineering in Chungbuk National University, Korea. Her research interests are in the field of Fuzzy Measures \& Fuzzy Integrasl, Gesture Recognition, and Serious Games.

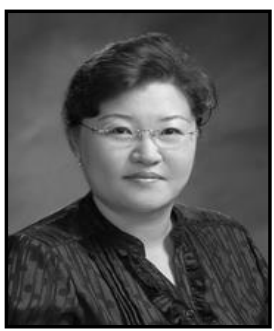

\section{Bong-Hee Kang}

Tri et Mono, Chungbuk Do, Korea. 
International Journal of Control and Automation Vol. 8, No. 6 (2015) 